\title{
Interleukin 12 shows a better curative effect on lung cancer than paclitaxel and cisplatin doublet chemotherapy
}

Ting Yue ${ }^{1,2}$, Xiaodong Zheng ${ }^{1,2}$, Yaling Dou ${ }^{1,2}$, Xiaohu Zheng ${ }^{1,2}$, Rui Sun ${ }^{1,2}$, Zhigang Tian ${ }^{1,2^{*}}$ and Haiming Wei ${ }^{1,2^{*}}$

\begin{abstract}
Background: Interleukin 12 (IL-12) is a cytokine that has been reported to exhibit potent tumoricidal effects in animal tumor models. A combined approach using Paclitaxel and platinum-based doublet chemotherapy is the most commonly used backbone regimen for treating lung cancer. Despite numerous studies regarding the anti-tumor effects of IL-12 and the widespread use of conventional chemotherapy, few direct comparisons of IL-12 and conventional chemotherapy in the treatment of lung cancer have been performed.
\end{abstract}

Methods: We compared IL-12 to paclitaxel and cisplatin doublet chemotherapy in terms of efficacy against lung cancer in mouse models. The antitumor effect was measured by survival assays, histological analyses and imaging analyses. The cytokine levels were assessed using enzyme linked immunosorbent assay (ELISA) and flow cytometry (FACS). The spleen sizes were measured. CD31, CD105 and Vascular endothelial growth factor receptor 3 (VEGFR3) were analyzed using immunofluorescence. Matrix metalloprotein-9 (MMP-9) and cadherin $1(\mathrm{CDH} 1)$ transcript levels were measured by quantitative PCR. Tumor cells apoptosis were examined by Tunel assay.

Results: The results showed that IL-12 treatment inhibited lung tumor growth, resulting in the long-term survival of lung cancer-bearing mice. Further examination revealed that IL-12 rapidly activated NK cells to secrete IFN- $\gamma$, resulting in the inhibition of tumor angiogenesis. In contrast, paclitaxel and cisplatin doublet chemotherapy did not show the expected efficacy in orthotopic lung cancer models; the IFN- $\gamma$ levels were not increased after this treatment, and the number of peripheral lymphocytes was reduced.

Conclusion: Together, these animal model data indicate that IL-12 shows a better curative effect than PTX + CDDP doublet chemotherapy.

Keywords: Interleukin-12, Lung cancer, Chemotherapy, Natural Killer cells, Interferon- $\gamma$, Angiogenic

Abbreviations: BSA, Bovine serum albumin; CD, Cluster of differentiation; CDDP, Cisplatin; ELISA, Enzyme linked immunosorbent assay; FACS, Flow cytometric; H\&E, Hematoxylin and eosin; IFN- $\gamma$, Interferon- $\gamma$; IL, Interleukin; IP-10, IFN- - -inducible protein 10; LLC, Lewis lung carcinoma; MHC, Major histocompatibility

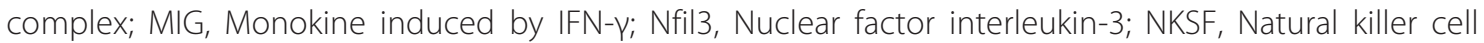
stimulatory factor; NS, Normal saline; NSCLC, Non-small cell lung cancer; PTX, Paclitaxel; SCLC, Small cell lung cancer; SD, Stable disease; Th, T-helper; VEGFR3, Vascular endothelial growth factor receptor 3;

VEGFR3, vascular endothelial growth factor receptor 3; WT, Wild type

\footnotetext{
* Correspondence: tzg@ustc.edu.cn; ustcwhm@ustc.edu.cn

${ }^{1}$ Institute of Immunology, School of Life Sciences, University of Science and

Technology of China, Hefei, Anhui, China

Full list of author information is available at the end of the article
} 


\section{Background}

Lung cancer is one of the most commonly diagnosed cancers and the leading cause of cancer deaths globally, causing more than 1.4 million deaths annually $[1,2]$. Paclitaxel (PTX) and cisplatin (CDDP) doublet chemotherapy is one of the first-line treatments for patients with non-small cell lung cancer (NSCLC) and small cell lung cancer (SCLC) [3-5]. Although this chemotherapeutic approach can be effective, the survival rates remain low $[3,6,7]$. Therefore, effective therapeutic approaches such as immunotherapies are urgently needed.

Interleukin 12 (IL-12) is a pro-inflammatory cytokine that was originally identified as a natural killer (NK) cell stimulatory factor (NKSF) and a cytotoxic lymphocyte maturation factor $[8,9]$. Physiologically, IL-12 has been implicated in the stimulation of $\mathrm{NK}$ and $\mathrm{T}$ cell proliferation, the enhancement of $\mathrm{NK}$ and $\mathrm{CD}^{+} \mathrm{T}$ cell cytolytic activity and the induction of cytokine production, particularly IFN- $\gamma[10,11]$. Furthermore, IL-12 promotes the differentiation of $\mathrm{T}$ helper $1\left(\mathrm{~T}_{\mathrm{H}} 1\right)$ cells, thereby bridging innate and adaptive immunity [12, 13]. Mice lacking the IL-12 subunit p35 showed the early appearance and development of a greater number of papilloma compared with wild-type (WT) mice. Accordingly, the growth of B16 melanomas is faster in mice that are deficient in the IL-12 receptor chain IL-12R $\beta 2$ compared to WT mice [14, 15]. Exogenously administered IL-12 exhibits impressive anti-tumor effects in different murine tumor models such as sarcoma, melanoma, lung carcinoma and breast carcinoma [16-18]. Although IL-12 has certain side effects, its curative effect is significant. The results from IL-12 phase I/II trials in patients with B-cell lymphoma or Kaposi sarcoma offer great clinical prospects [19, 20]. Furthermore, recent studies have shown that IL-12 plus IL-18 can restore intratumoral NK cell functions in MHC (major histocompatibility complex) class I-deficient tumors [21, 22].

PTX is a cytoskeletal drug that targets tubulin. By stabilizing microtubules, PTX arrests the cell cycle in the G0/G1 and G2/M phases and induces cancer cell death [23]. CDDP is a platinum coordination compound that has the ability to crosslink the purine bases in DNA, causing DNA damage and subsequently inducing apoptosis in cancer cells [24]. A combined approach using PTX and platinum-based doublet chemotherapy is the most commonly used backbone regimen for treating NSCLC and SCLC [3-5]. The effective induction of chemotherapy has been shown to be beneficial for the survival of some lung cancer patients. However, a few retrospective studies have shown that the benefits of chemotherapeutic agents were small for patients with stable disease (SD), and many cases have shown the failure of conventional chemotherapy in treating advanced NSCLC $[25,26]$.
In the present study, we generated two different orthotopic lung cancer models and showed that IL-12 administration could suppress tumor growth in these models, leading to long-term survival compared with the controls. In contrast, PTX + CDDP doublet chemotherapy did not improve survival compared with the control in the lung cancer models. To explore the mechanisms underlying this phenomenon, we examined IFN- $\gamma$, which is an important anti-tumor effector molecule, and found that the IFN- $\gamma$ levels were significantly increased after IL-12 administration. Further examination revealed that NK cells were quickly activated and secreted IFN- $\gamma$ a few hours after IL-12 administration. In contrast, the IFN- $\gamma$ levels were not increased after PTX and CDDP doublet chemotherapy, and the number of peripheral lymphocytes was reduced. Furthermore, the anti-tumor activity of IL-12 was found greatly reduced in both NK cell-deficient mice and IFN- $\gamma$-deficient mice, suggesting that NK cells and IFN- $\gamma$ are the primary factors that mediate the anti-tumor effects of IL-12 in lung cancer models. Moreover, we observed that IL-12 inhibited tumor angiogenesis via an IFN- $\gamma$-dependent mechanism. These results suggest that IL-12 showed a greater efficacy than PTX + CDDP doublet chemotherapy and may thus provide an effective strategy for treating lung cancer.

\section{Methods \\ Mice and cell lines}

Female C57BL/6 and BALB/c mice at 7-8 weeks of age were purchased from the Shanghai Laboratory Animal Center (Shanghai, China). Female IFN- $\gamma^{-/-}$ mice on a C57BL/6 background were a generous gift from Dr. Shaobo Su (Shantou University Medical College, Shantou, China). Female $\mathrm{CD}^{-/-}$and $\mathrm{CD} 8^{-/-}$ mice, all on a C57BL/6 background, were obtained from Prof. Zhexiong Lian (University of Science and Technology of China, Hefei, China). Female Nuclear factor interleukin-3 (Nfil3) $)^{-1-}$ mice (without NK cells) on a C57BL/6 background were a kind gift from Prof. Tak Wah Mak (University of Toronto, Toronto, Canada). All mice were maintained under specific pathogen-free conditions, and all animal experimental protocols were approved by the Ethics Committee of Animal Experiments of the University of Science and Technology of China (Approval Number: USTCACUC1201051).

LLC cells were obtained from the Chinese Academy of Sciences Cell Bank (Shanghai, China) and cultured at $37{ }^{\circ} \mathrm{C}$ with $5 \% \mathrm{CO}_{2}$ in DMEM supplemented with $10 \%$ FCS. CT26 cells (a generous gift from Prof. Xuetao Cao, Zhejiang University School of Medicine, Hangzhou, China) were cultured at $37{ }^{\circ} \mathrm{C}$ with $5 \% \mathrm{CO}_{2}$ in $\mathrm{RPMI}$ 1640 supplemented with $10 \%$ FCS. 


\section{Tumor generation and treatment}

C57BL/6 mice were injected intrapleurally with $5 \times 10^{5}$ LLC cells in $0.1 \mathrm{ml}$ of PBS to generate an orthotopic lung cancer model. The tumor-bearing mice were divided randomly into four groups for imaging and histological analyses or into five groups for survival analysis. These groups were administered saline, single doses of PTX $(5 \mathrm{mg} / \mathrm{kg}$ of body weight, Cat. No. H20063662, Beijing HWELLS Co., Ltd.) and CDDP (5 mg/kg of body weight, Cat. No. H20063662, Nanjing Pharmaceutical Co., Ltd.), three doses of PTX + CDDP ( $5 \mathrm{mg} / \mathrm{kg}$ of body weight), and a combined treatment with recombinant murine $\mathrm{IL}-12$ (rmIL-12; $12 \mu \mathrm{g} / \mathrm{kg}$ of body weight, Cat. No. 210-12, PeproTech). PTX+ CDDP were injected intravenously 5 days after tumor inoculation. For the survival analysis, the tumor-bearing mice were administered three doses of PTX + CDDP once a week. Eight days after tumor inoculation, three doses of IL-12 were injected subcutaneously into the forelimb root of the mice once every other day. Two days later, this treatment regimen was repeated one time.

To establish a lung metastasis model, BALB/c mice received intravenous tail vein injections of $4 \times 10^{4}$ CT26 cells in $0.2 \mathrm{ml}$ of PBS. With the exception of the group that received three doses of PTX+ CDDP, the groups and treatments were the same as those described above.

To generate lung cancer models, $\mathrm{Nfil}^{-/-}, \mathrm{CD}^{-/-}$, $\mathrm{CD}^{-/-}$and IFN $-\gamma^{-/-}$mice were injected with LLC cells as described above. PTX and CDDP were not administered to these models, and the IL-12 treatment was administered as described above.

\section{Bioluminescence imaging and analysis}

The plasmid vector pcDNA3.1 (Cat. No. V790-20, Invitrogen) was engineered and modified to express luciferase (pcDNA3.0-Luc). LLC and CT26 cells were transfected with pcDNA3.0-Luc, and the clones with strong bioluminescence signals $(150 \mu \mathrm{g} / \mathrm{ml}$ luciferin, Cat. No. LUCK-1G, Gold Biotechnology) were expanded and injected into mice to generate a lung cancer model. After intravenous tail vein injection of luciferin (150 $\mathrm{\mu g} / \mathrm{g}$ body weight), the mice were anesthetized with isoflurane and placed into an IVIS imaging chamber (Caliper Life Sciences, USA). To analyze the bioluminescence images, bioluminescent signal emission regions in whole mice or lung tissue samples were designated, and the total photon flux per second was quantified and analyzed using the Living Image software (Xenogen, USA).

\section{Flow cytometric analysis}

The spleens of mice were harvested and weighed. Spleen size was calculated as (width $\times$ length $\times$ thickness) $/ 2$. To harvest splenocytes, spleens were cut into small pieces and passed through 200-gauge mesh. Splenocytes were harvested after RBC lysis and washing. For the intracellular cytokine analysis of IFN- $\gamma$, the splenocytes $\left(1 \times 10^{6}\right.$ cell $/ \mathrm{ml}$ ) were incubated for $4 \mathrm{~h}$ with PMA (30 ng/ml, Cat. No. P1585, Sigma-Aldrich), ionomycin (1 $\mu \mathrm{g} / \mathrm{ml}$, Cat. No. 407952, Merck) and monensin (5 $\mu \mathrm{g} / \mathrm{ml}$; Cat. No. 46468, Sigma-Aldrich). Subsequently, the splenocytes were washed and blocked to eliminate non-specific binding using anti-CD16/32 (2.4G2; BD Biosciences). FITC-anti-NK1.1 and APC-anti-CD3 (BD Biosciences, USA) were used to stain the extracellular markers. Then, the cells were fixed, permeabilized, and stained with PEanti-IFN- $\gamma$. The stained cells were analyzed using a FACSCalibur flow cytometry system (BD Biosciences), and the data were analyzed using the FlowJo 7.6 software (Treestar, USA).

\section{ELISA for cytokine detection}

Mouse serum was collected 1 day after treatment. The levels of IFN- $\gamma$ were measured using an IFN- $\gamma$ ELISA kit (Cat. No. DKW12-2000-096, Dakewe Biotech Company) according to the manufacturer's instructions.

\section{Hematoxylin and eosin staining}

For the histological analysis, the lung and tumor tissue sections were fixed in $10 \%$ phosphate-buffered formalin $(\mathrm{pH} 7.2)$ and embedded in paraffin. The tissue sections (6- $\mu$ m-thick) were affixed to the sides, deparaffinized, stained with $H \& E$ and examined under a light microscope (Zeiss, Germany).

\section{Immunofluorescence staining}

Lung tumor samples were embedded in optimal cutting temperature compound. Cryosections ( $9 \mu \mathrm{m}$ thick) were air-dried, fixed for $10 \mathrm{~min}$ at room temperature using a 1:1 mixture of acetone and methanol and subsequently blocked to eliminate non-specific binding using $0.5 \%$ bovine serum albumin (BSA) in PBS for $1 \mathrm{~h}$. The cryosections were incubated with PE-anti-CD31 (BD Biosciences), rabbit anti-VEGFR3 (Cat. No. ab27278, Abcam), PE-CD105 (BD Biosciences), PE-CD3 and APC-F4/ 80 (BD Biosciences) for $12 \mathrm{~h}$ at $4{ }^{\circ} \mathrm{C}$. After the cryosections were washed with PBS, they were incubated with FITC-goat anti-rabbit IgG (Cat. No. sc-2012, Santa Cruz Biotechnology) for $2 \mathrm{~h}$ at $37^{\circ} \mathrm{C}$ and subsequently washed with PBS. The slides were stained with DAPI (Cat. No. sc-3598, Santa Cruz Biotechnology) for 2 min. Then, the slides were washed in PBS, and coverslips were mounted onto the slides using anti-fade reagent (Cat. No. P36930, Life Technologies). The images were acquired using a Zeiss LSM 710 confocal microscope (Zeiss, Germany). The expression regions of CD31, VEGFR3 and CD105 were quantified and analyzed using the Image-Pro Plus software (Media Cybernetics, USA). 


\section{Quantitative RT-PCR analysis}

Total RNA from tumor tissues was isolated using TRIzol reagent (Catalog No. 51-0700, Invitrogen, Camarillo, CA, USA). RNA was then reverse transcribed using Moloney murine leukemia virus reverse transcriptase (Catalog No. 51-0700, Invitrogen). Quantitative PCR analysis was performed according to the instructions using a SYBR Premix Ex Taq (Takara Japan). For analysis, the expression of target genes was normalized to the $\beta$-actin. All primers were synthesized by Sangon Biotech (China). The primers used to amplify $\beta$-actin were $\beta$-actin-F (5' - TTG CCG ACA GGA TGC AGA A-3') and $\beta$-actin-R (5' - GCC GAT CCA CAC GGA GTA CTT $\left.-3^{\prime}\right)$. The primers used to amplify MMP-9 were MMP-9-F (5' - GCA GAG GCA TAC TTG TAC CG -3') and MMP9-R (5' - TGA TGT TAT GAT GGT CCC ACT TG -3'). The primers used to amplify CDH1 were CDH1-F (5'CAG GTC TCC TCA TGG CTT TGC -3') and CDH1-R (5'- CTT CCG AAA AGA AGG CTG TCC -3'). The primers used to amplify IFN- $\gamma$ were IFN- $\gamma-\mathrm{F}\left(5^{\prime}-\mathrm{AAC}\right.$ GCT ACA CAC TGC ATC T -3') and IFN- $\gamma-\mathrm{R}\left(5^{\prime}\right.$ - GAG CTC ATT GAA TGC TTG G -3').

\section{Tunel analysis}

LLC tumor cells were first co-cultured with PTX + CDDP (same concentration used in mice) for $12 \mathrm{~h}$. Then, these cells were examined by micro-imaging and Tunel. Cryosections of tumor tissues were also examined by Tunel. Tunel analysis was performed according to the manufacturer's instructions using a One Step TUNEL Apoptosis Assay Kit (Beyotime Biotechnology China). The images were acquired using a OLYMPUS IX81 inverted microscope (OLYMPUS, Japan) and a Zeiss LSM 710 confocal microscope (Zeiss, Germany).

\section{Statistical analysis}

The data are shown as the means \pm standard error of the mean (SEM). Significant differences between more than two groups were determined using ANOVA. Comparisons between two groups were performed using twotailed unpaired Student's $t$-tests (*, $P<0.05$; **, $P<0.01$ ). Survival curves were estimated using the Kaplan-Meier method, and differences between the groups were determined using the log-rank test at a minimal $P$ value.

\section{Results}

IL-12 shows more efficacy than PTX + CDDP doublet chemotherapy in orthotopic lung cancer models

To test the efficacy of IL-12 and PTX + CDDP doublet chemotherapy in the treatment of lung cancer, we generated two different lung cancer models. As shown in Fig. 1, after treatment with IL-12 or chemotherapy in combination with IL-12 (PTX + CDDP + IL-12), markedly fewer lung tumor nodes (the bioluminescent signal emission region, with the arrows indicating areas of the hematoxylin and eosin ( $\mathrm{H} \& \mathrm{E})$-stained sections) were detected in the treatment groups compared with both the control group and the chemotherapy-treated LLC lung cancer models. We also conducted a survival assay. As shown in Fig. 1e, tumor-bearing mice treated with IL-12 or PTX + CDDP + IL-12 showed significant long-term survival compared with the control and chemotherapy treatment groups. Remarkably, the mice treated with IL12 or PTX + CDDP + IL-12 survived more than 80 days (Fig. 1e), which suggests the anti-tumor efficacy of IL-12 as monotherapy or in combination with PTX + CDDP. Although PTX and CDDP have been used as a first-line chemotherapy treatment for lung cancer, these data showed that neither a single dose nor three doses of PTX-CDDP doublet chemotherapy were sufficient to extend the lives of tumor-bearing mice significantly or to suppress tumor growth (Fig. 1b-e). Similar results were shown in the CT26 lung metastasis model (Fig. 2a-d). In this lung cancer model, the PTX + CDDP + IL-12 treatment showed a better therapeutic effect than the PTX + CDDP treatment alone and resulted in long-term survival (Fig. 2c). We also counted the visible tumor nodes and measured the weight of tumor and lung tissues as a whole after completion of the treatments. These data revealed that the IL-12 or PTX + CDDP + IL12 treated mice had less visible lung tumor nodes and lower lung tumor weight compared to the PTX + CDDP or control groups (Additional file 1: Figure S1). To assess whether PTX + CDDP has an effect on tumor cells, in vitro and in vivo experiments were performed. The results showed that PTX + CDDP (same concentration used in mice) treatment resulted in LLC cell apoptosis in vitro, however, no apoptosis was detected in LLC tumor tissues after PTX + CDDP treatment (Additional file 2: Figure S2). Based on these data, IL-12 showed a greater efficacy than PTX + CDDP doublet chemotherapy in the two different lung cancer models.

\section{IL-12 activates the immune system and rapidly stimulates NK cells to secrete IFN- $\gamma$}

To investigate the effects of IL-12 and PTX + CDDP doublet chemotherapy on the immune system, tumorbearing mice were treated with IL-12, PTX + CDDP or NS and then sacrificed. Surprisingly, we observed that the spleens of tumor-bearing mice treated with IL-12 or PTX + CDDP + IL-12 were markedly enlarged but that the spleens of tumor-bearing mice treated with PTX + CDDP alone were slightly shrunken compared with the spleens of control mice (Additional file 3: Figure S3). Subsequently, we isolated mononuclear cells from the spleens of these mice and quantified the cells. Notably, the number of mononuclear cells from the spleens of tumor-bearing mice treated with IL-12 or 

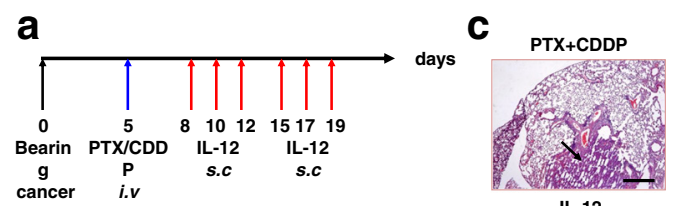

IL-12

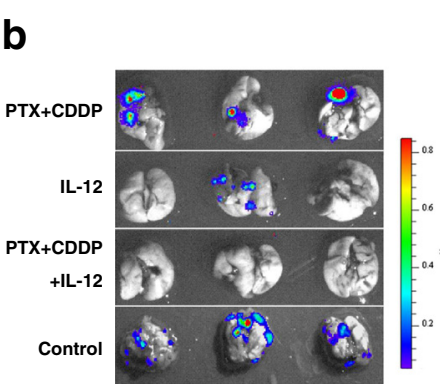

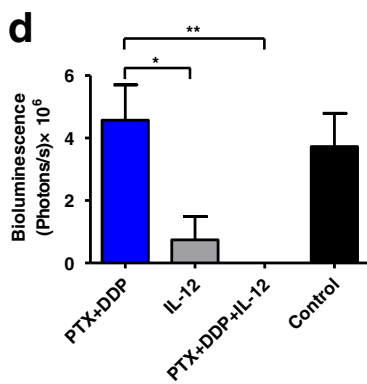

e

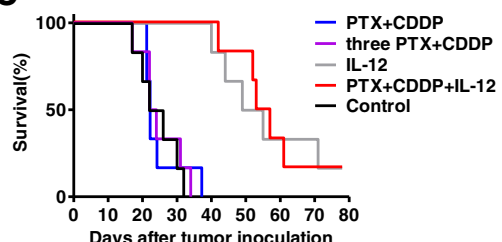

Fig. 1 Comparison of the efficacy of IL-12 and PTX + CDDP doublet chemotherapy on LLC tumor-bearing mice. a Treatment regimen in orthotopic lung cancer models. Tumor-bearing mice were treated with PTX + CDDP + IL-12, IL-12, PTX + CDDP, saline (as shown). $\mathbf{b}$ Imaging of lung tumor tissues. Fewer lung tumor nodes were detected in IL-12 and PTX + CDDP + IL-12 treatment groups as compared to PTX + CDDP and control groups. c Pathological examination also showed that fewer lung tumor nodes were detected in IL-12 and PTX + CDDP + IL-12 treatment groups as compared to PTX + CDDP and control groups. The arrows indicate the areas of the tumor nodes (magnification $\times 100$; scale bar, $200 \mu \mathrm{m}$ ). d The Imaging results were quantified and analyzed. Bioluminescence (photos/s) indicated that, after IL-12 or PTX + CDDP + IL-12 treatment, living tumor cells were markedly decreased compared with PTX + CDDP and control groups $(n=3 ;$ means \pm SEM, * $P<0.05)$. e The survival (Kaplan-Meier) curves of the treated animals are shown; Prolonged survival was observed in IL-12 or PTX + CDDP + IL-12 group as compared to PTX + CDDP or control group (log-rank test, $P<0.01)$

PTX + CDDP + IL-12 increased significantly compared with both the PTX + CDDP-treated mice and the control mice (Fig. 3e). We examined the IFN- $\gamma$ transcript levels in tumor tissues of different groups by quantitative PCR. The results showed that the IFN- $\gamma$ transcript levels in the tumor tissues of the IL-12 or PTX + CDDP + IL-12 groups were much higher than those in the control group that was treated with PTX + CDDP alone (Fig. 3b). We also used ELISA to measure the serum IFN- $\gamma$ levels in tumor-bearing mice following treatment. As expected, the serum IFN- $\gamma$ levels in the tumor-bearing mice that were treated with IL-12 or PTX + CDDP + IL-12 were much higher than were those in the control mice. By contrast, almost no IFN- $\gamma$ was detected in the sera of tumor-bearing mice treated with PTX + CDDP (Fig. 3c). To further identify the immune cell subpopulation responsible for IFN- $\gamma$ production, we examined the expression of intracellular IFN- $\gamma$ using flow cytometry (Fig. 3a). Interestingly, IFN- $\gamma$ secretion by NK cells increased markedly and rapidly following IL-12 or PTX + CDDP + IL-12 treatment. However, the NK cells showed no IFN- $\gamma$ secretion after PTX + CDDP treatment compared with the control (Fig. 3d). These data suggest that IL-12 can activate NK cells rapidly to produce IFN- $\gamma$, whereas PTX + CDDP not only failed to promote IFN- $\gamma$ production but also reduced the number of peripheral lymphocytes to some extent.
NK cells and IFN- $\gamma$ are essential for the anti-tumor effects of IL-12

Although earlier results indicate that NK cells in tumor-bearing mice can be activated to produce IFN$\gamma$ following IL-12 treatment, the role of NK cells in the IL-12-mediated lung tumor suppression still needs to be investigated. To further confirm the roles of NK and IFN- $\gamma$ in the anti-tumor effects of IL-12, $\mathrm{Nfil}^{-/-}$(without NK cells), CD4 ${ }^{-1-}, \mathrm{CD} 8^{-1-}, \mathrm{IFN}-\gamma^{-/-}$ and WT mice were injected with LLC tumor cells to establish lung cancer models. Subsequently, the tumor-bearing mice were treated with IL-12 or NS, and tumor growth was monitored via whole-body imaging (Figs. 4a and 5a). Remarkably, the tumors in $\mathrm{Nfil3}^{-/-}$mice or in IFN- $\gamma^{-/-}$mice grew significantly faster than did those in the WT, $\mathrm{CD}^{-1-}$ and $\mathrm{CD} 8^{-/-}$ mice, as indicated by the bioluminescent signal emission region. Furthermore, IL-12 treatment inhibited tumor growth in the WT mice but not in the $\mathrm{Nfil}^{-/-}$and IFN- $\gamma^{-1-}$ mice (Fig. $4 \mathrm{a}$ and $5 \mathrm{a}-\mathrm{c}$ ). These results were also confirmed by survival analyses, which indicated that the tumor-bearing WT mice exhibited significant long-term survival compared with the tumor-bearing $\mathrm{Nfil}^{-/-}$and $\mathrm{IFN}-\gamma^{-/-}$mice after treatment with IL-12 (Figs. $4 \mathrm{~b}$ and $5 \mathrm{~b}$ ). We also performed an immunofluorescence assay to evaluate $\mathrm{T}$ cell and macrophage infiltration in tumors. However, similar macrophage recruitment was observed in all 


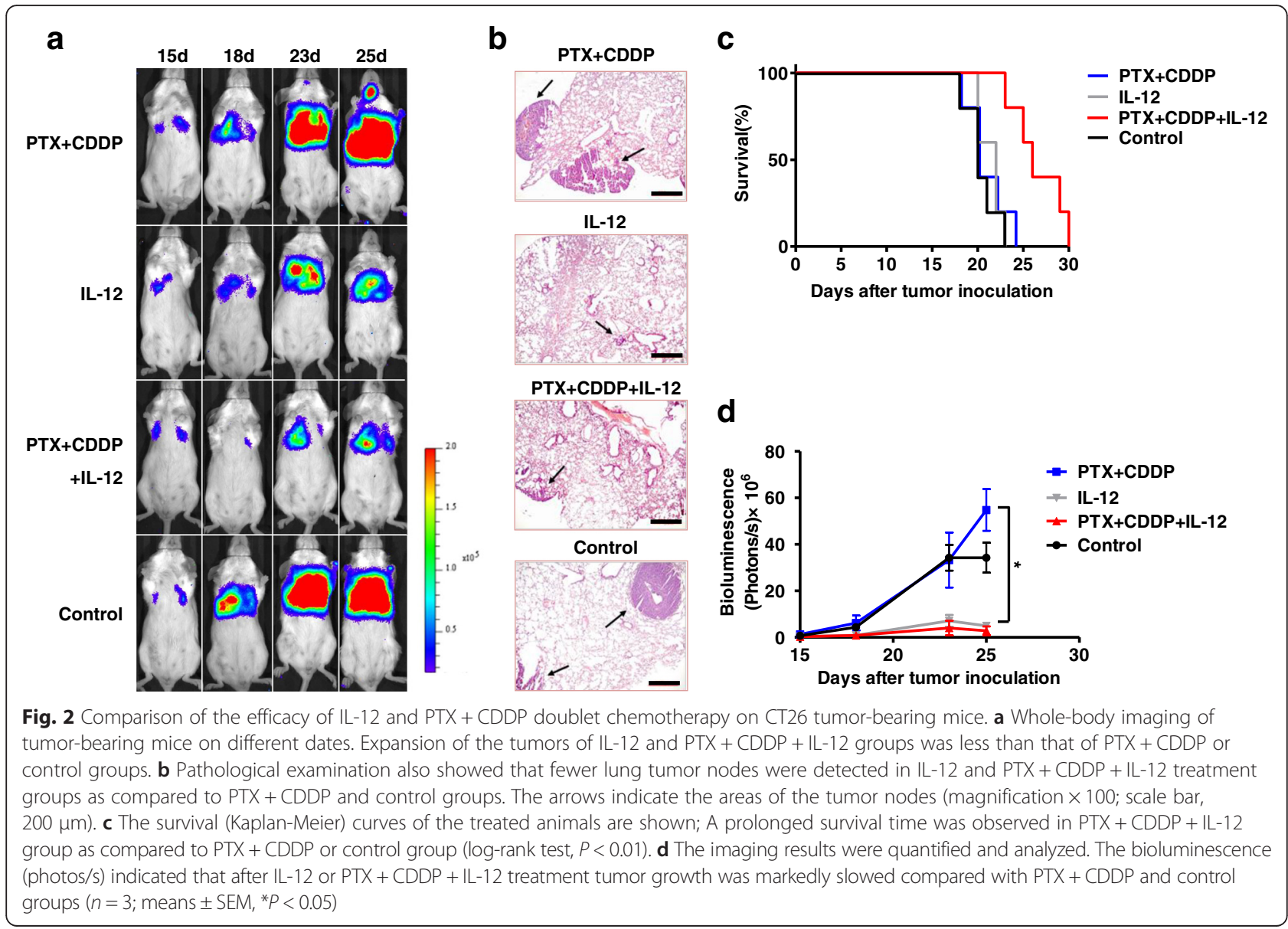

groups, and all tumor sections exhibited a minimal infiltration of $\mathrm{T}$ cells (Additional file 4: Figure S4). Collectively, these data indicate that NK cells and IFN- $\gamma$ play essential roles in the anti-tumor effects of IL-12 in these lung cancer models.

\section{IL-12 via mediation of IFN- $\gamma$ suppresses tumor angiogenesis}

To investigate whether IL-12 via mediated IFN- $\gamma$ expression suppresses tumor angiogenesis in lung cancer, IFN- $\gamma^{-/-}$and WT mice were tumor-burdened and subsequently treated with IL-12. After the mice received treatments, lung tumor tissue sections were processed, and the frozen lung tumor tissue sections were stained with anti-CD31 and anti-vascular endothelial growth factor receptor 3 (VEGFR3). Confocal immunofluorescence imaging showed that the lung tumor tissues from IFN $-\gamma^{-1-}$ mice had higher levels of CD31 and VEGFR3 expression than did those from WT mice (Fig. 6a). Moreover, IL-12 or PTX + CDDP + IL-12 treatment reduced CD31 and VEGFR3 expression in the lung tumor tissues of WT mice (Fig. 6a and b). In addition, we observed the colocalization of CD31 and VEGFR3 in the lung tumor tissues of WT mice after IL-12 or PTX + CDDP + IL12 treatment. However, IL-12 or PTX + CDDP + IL-12 treatment did not reduce CD31 and VEGFR3 expression in the lung tumor tissues of IFN- $\gamma^{-/-}$mice. In these animals, CD31 and VEGFR3 did not co-localize and showed dysregulated expression (Fig. 6a). We also examined another vascular marker CD105 and found that its expression was reduced in wildtype but not in IFN- $\gamma^{-/-}$tumor-bearing mice after IL-12 treatment (Fig. 6c and d). Reduced blood vessels may cause an increase in hypoxia that result in more invasive phenotype $[27,28]$. To evaluate invasive phenotype of different groups, we examined the transcript levels of matrix metalloprotein-9 (MMP-9) and cadherin 1 (CDH1) in para-carcinoma tissue. The results showed that the MMP-9 transcript level was decreased after IL-12 treatment; however, the CDH1 transcript level did not change significantly (Additional file 5: Figure S5). These results may suggest that treatment with IL-12 does not result in a more invasive phenotype. Taken together, these data indicate that the IL-12 via mediated inhibition of tumor angiogenesis is IFN- $\gamma$ dependent and may suppress tumor growth. 


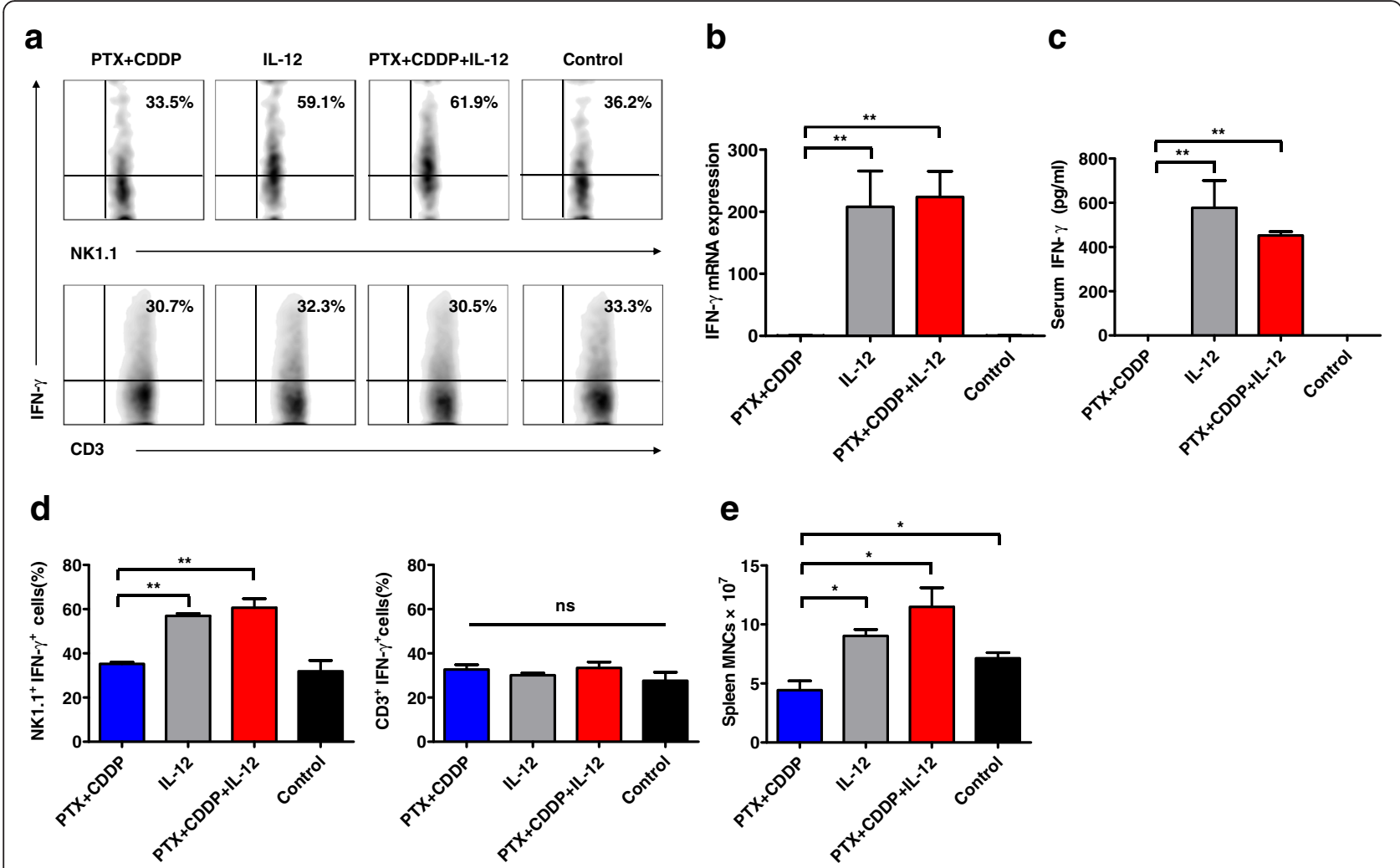

Fig. $3 \mathrm{IL}-12$ activates the immune system and rapidly stimulates NK cells to secrete IFN- - . a Flow cytometry analysis of IFN- - -producing lymphocytes isolated from the spleens of tumor-bearing mice. The expression of IFN- $\gamma$ in NK cells increased significantly after IL-12 or PTX + CDDP + IL-12 treatment as compared to PTX + CDDP treatment or control. $\mathbf{b}$ IFN- $\gamma$ transcript levels in tumor tissues of different groups were measured by quantitative PCR. The IFN- $\gamma$ transcript levels in IL-12 or PTX + CDDP + IL-12 groups were much higher than those in the PTX + CDDP or control groups. $(n=3 ;$ means \pm SEM, $\left.{ }^{* *} P<0.01\right)$. c The IFN- $\gamma$ serum concentration of different treatments in tumor-bearing mice. The serum IFN- $\gamma$ levels in IL-12 or PTX + CDDP + IL-12 groups were much higher than those in the PTX + CDDP or control groups. $\left(n=3\right.$; means \pm SEM, $\left.{ }^{* *} P<0.01\right)$. $\mathbf{d}$ The percentages of NK1. $1^{+} I F N-\gamma^{+}$and $\mathrm{CD}^{+} \mathrm{IFN}-\gamma^{+}$cells in the spleens of tumor-bearing mice in different groups. The percentages of NK1. $1^{+} \mathrm{IFN}-\gamma^{+}$in IL-12 or PTX $+\mathrm{CDDP}+\mathrm{IL}-12 \mathrm{groups}$ were much higher than those in the PTX + CDDP or control groups. $\left(n=6\right.$; means \pm SEM, $\left.{ }^{*} P<0.01\right)$. e The spleen mononuclear cell numbers from tumor-bearing mice. More spleen mononuclear cells were found in the IL-12 or PTX + CDDP + IL-12 groups as compared to PTX + CDDP and control groups. Less spleen mononuclear cells were found in the PTX + CDDP group compared to the control group $\left(n=6\right.$; means \pm SEM, $\left.{ }^{*} P<0.05\right)$

\section{Discussion}

Lung cancer is the leading cause of cancer deaths worldwide $[1,2]$. Although traditional lung cancer treatments such as surgery, chemotherapy and radiotherapy remain widely used, the results of such treatments are not satisfactory [7]. Thus, different therapeutic approaches including immunotherapies are being studied.

As a type of immunotherapy, IL-12 has displayed significant anti-tumor effects in a variety of animal models [29-31]. However, conventional chemotherapy remains one of the most commonly used treatments for lung cancer. Therefore, comparing the efficacy of IL-12 with conventional chemotherapies or testing the efficacy of a combination of IL-12 and chemotherapy against lung cancer is important. PTX + CDDP doublet chemotherapy is recommended for treating NSCLC and SCLC $[5,32]$. However, our preliminary results showed that PTX + CDDP treatment resulted in LLC cell apoptosis in vitro, and no apoptosis was detected in LLC tumor tissues after PTX + CDDP treatment (Additional file 2: Figure S2). Here, we established two different orthotopic lung cancer models (Figs. 1 and 2). In contrast to subcutaneous tumor models, tumor nodes bud from lung tissues in orthotopic lung cancer models, thereby mimicking actual lung cancer conditions. To determine the treatment and dosage regimens of chemotherapy and IL-12, we referred to previous reports $[16,33-35]$ and the results of preliminary experiments.

Interestingly, IL-12 administration via axillary subcutaneous injection significantly inhibited lung tumor growth, resulting in the long-term survival of tumorbearing mice (Figs. 1 and 2). However, despite being administered in either single or multiple doses, PTX + CDDP doublet chemotherapy did not show the expected efficacy and improvement in the survival of the lung cancer models compared with the controls (Figs. 1 and 2). Conventional chemotherapy has been thought 


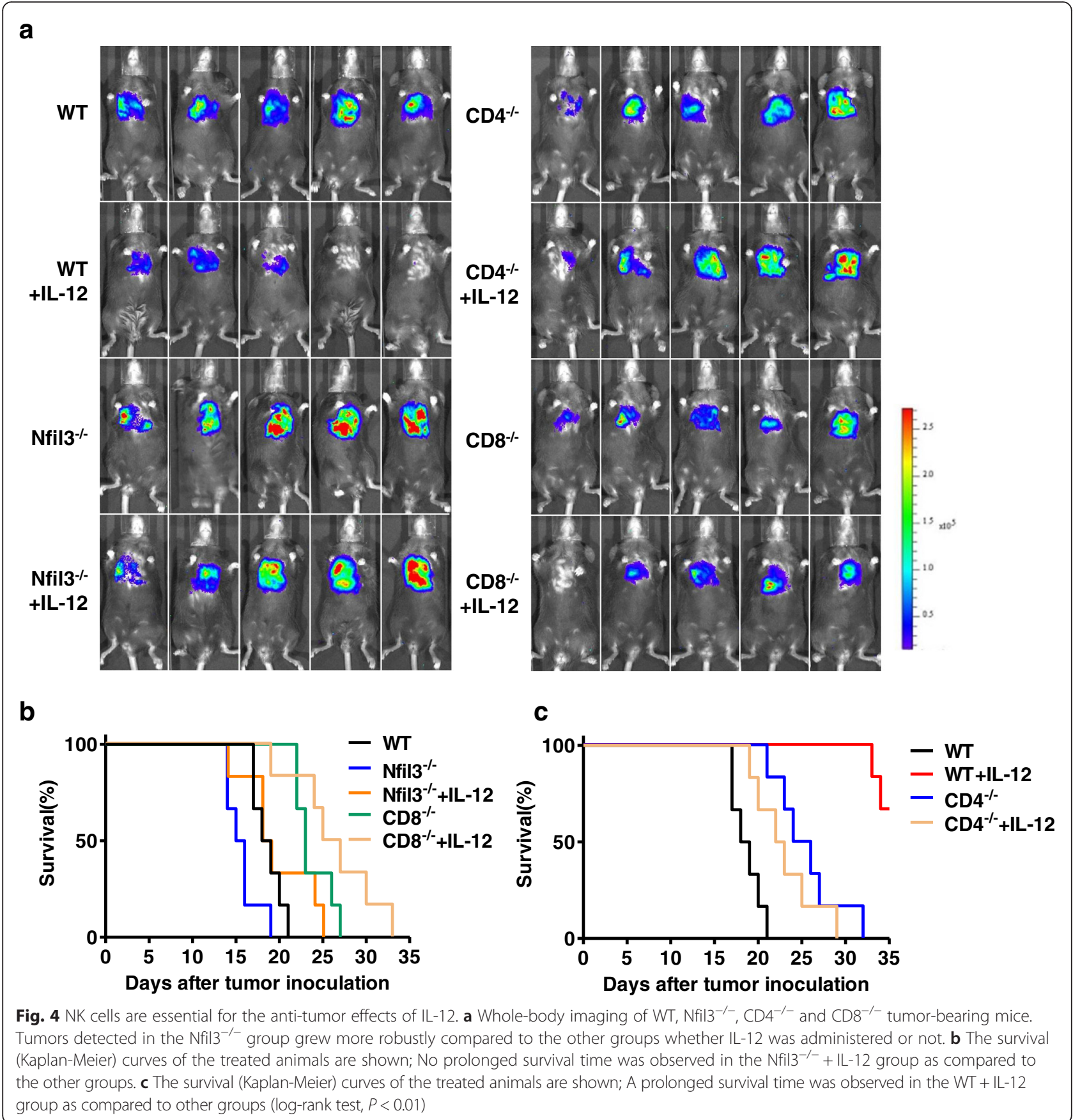

to act via the direct killing of tumor cells [36]. However, chemotherapy also affects other systems of the body, such as the immune system [37]. Differing views exist regarding the role of conventional chemotherapy on the immune system [36-38]. Evidence has suggested that conventional chemotherapy drugs such as cyclophosphamide may induce tumor cell death and stimulate the cross-presentation of dendritic cells (DCs) [36]. Reports have also demonstrated that PTX or docetaxel inhibited the NK cell-mediated killing of
K562 target cells effectively in vitro $[38,39]$. In the present study, the further optimization of the chemotherapy dosage regimen may bring results that are more reasonable. However, the decreased number of immune cells and the attenuation of the host immune system (Fig. 3) caused by PTX + CDDP treatment may have contributed to the uncontrolled tumor growth.

The anti-tumor mechanism of IL-12 is complex; previous studies have suggested that both innate and adaptive immunity are involved in the activity of IL- 


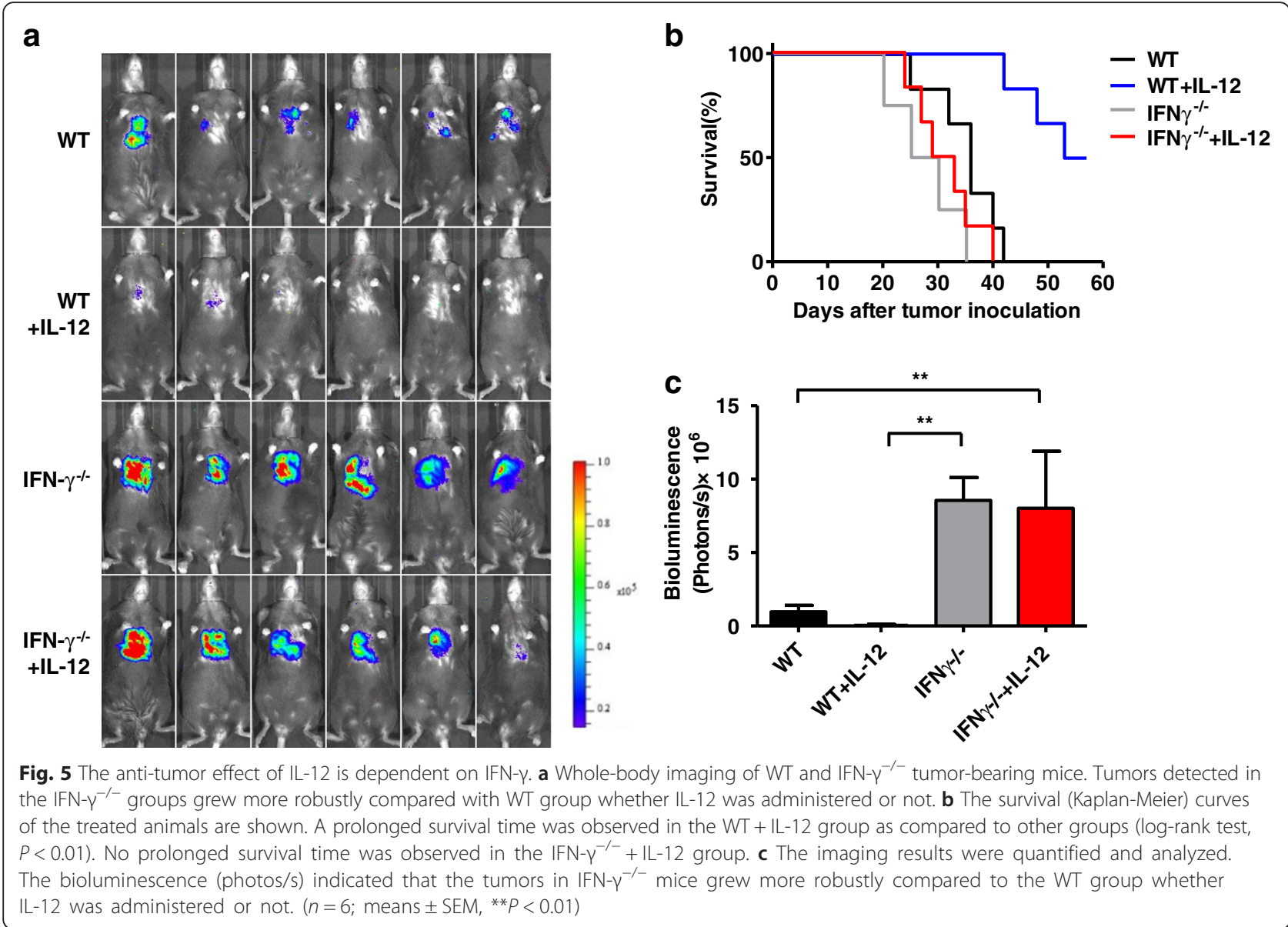

$12[17,40,41]$. The anti-tumor effect of IL-12 on sarcomas or adenomas, which are considered immunogenic cancers [42], is mediated by $\mathrm{CD}^{+}$or $\mathrm{CD}^{+} \mathrm{T}$ cells [16]. In other tumor models, such as EL4, the IL-12-induced inhibition of tumor growth was shown to depend on NK and NKT cells [41]. It seems that the anti-tumor immune responses induced by IL-12 can be divided into two categories: adaptive immunity mediated primarily via IL-12-induced $\mathrm{T}_{\mathrm{H}} 1$ polarization, in which $\mathrm{T}$ cells are the primary effector cells, and innate immunity mediated via IL-12-activated NK or other innate immune cells. In one tumor model, the category of the cellular response induced by IL-12 may depend on tumor immunogenicity. In this report, we further revealed that NK cells play a major role in the anti-tumor effects of IL12 on lung cancer (Fig. 4a, b). The inoculation of LLC cells induced a greater amount of tumor growth in NK cell-deficient mice $\left(\mathrm{Nifl}^{-/-}\right)$than in WT mice. Moreover, in contrast to WT mice, the tumor growth in NK celldeficient mice was not suppressed after IL-12 treatment (Fig. 4).

Given the importance of IFN- $\gamma$ for the anti-tumor effects mediated by IL-12 [40], we used IFN- $\gamma^{-1-}$ mice to further confirm the importance of this cytokine (Fig. 5).
The major source of IFN- $\gamma$ had not yet been elucidated, as both NK and T cells produce IFN- $\gamma$ after IL-12 administration $[18,43]$. Here, we revealed that NK cells can be activated rapidly and that intracellular IFN- $\gamma$ was detected in these cells six hours after IL-12 administration. Notably, T cells could not be activated as quickly (Fig. 3b, e). IFN- $\gamma$ and a cascade of other secondary and tertiary pro-inflammatory cytokines were reported to have a direct toxic effect on the tumor cells and cause tumor cell apoptosis [10]. Our results may suggest that IFN- $\gamma$ may delay the onset of vigorous tumor growth. IFN- $\gamma$ has also been reported to promote the inhibition of angiogenesis [44]. Subsequent experiments confirmed that $\mathrm{CD} 1^{+}$vessels in lung tumor tissue become expanded and disordered, particularly in the IFN $-\gamma^{-/-}$mice (Fig. 6). Vascular endothelial growth factor receptor 3 (VEGFR3), which is downregulated in quiescent adult vessels, is upregulated during angiogenesis [45, 46]. Moreover, VEGFR3 was abundantly expressed in lung tumor tissues, particularly in the IFN $-\gamma^{-/-}$mice. Importantly, the areas showing VEGFR3 expression did not overlap with $\mathrm{CD} 31^{+}$vessels in lung tumor tissue, suggesting the formation of new vessels. Further studies showed that CD31 and VEGFR3 expression was greatly 


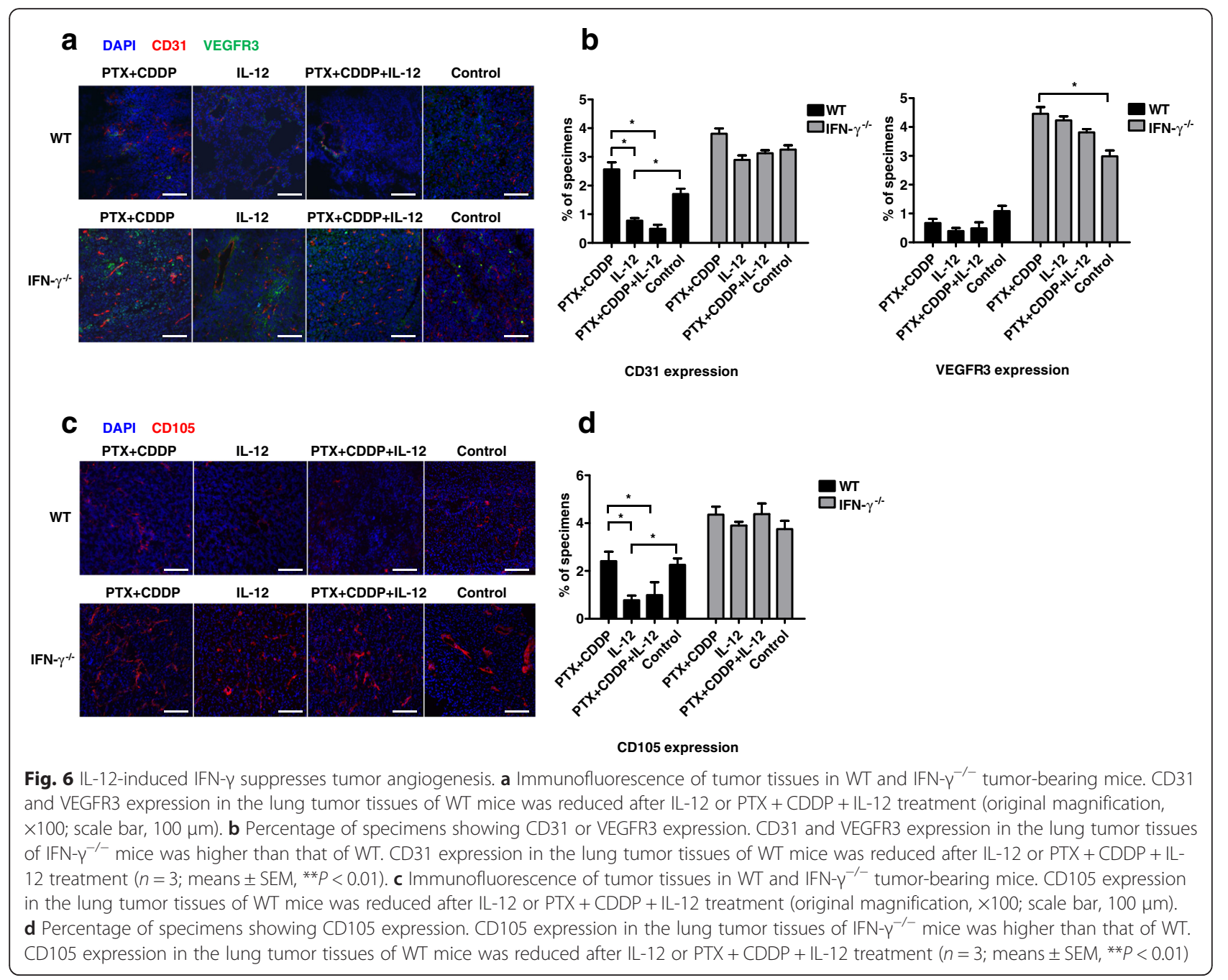

reduced after IL-12 treatment and that weakly expressed VEGFR3 co-localized with CD31. IFN- $\gamma$ may also induce the secretion of the chemokines IFN- $\gamma$-inducible protein 10 (IP-10) and monokine induced by IFN- $\gamma$ (MIG) $[47,48]$. These chemokines may induce alterations in the extracellular matrix remodeling process and decrease the expression of adhesion molecules from the endothelial cells $[11,49]$. These mechanisms may lead to the IL-12-mediated anti-angiogenic effect of IFN- $\gamma$.

Toxic side effects are an important factor, which determines a drug's clinical application. The Phase I and Phase II trials of IL-12 in patients with renal cancer were performed by the Genetics Institute. In the Phase I trial, the toxicity of IL-12 was acceptable. However, in the Phase II trial, the administration of IL-12 resulted in severe systemic toxicity that threatened patients' lives $[50,51]$. Subsequent investigations have found that the problem is triggered by the dosing regimen. In the Phase II study, the patients received consecutive high doses of IL-12 by intravenous injection. However, the Phase I trial gave patients various amounts of IL-12 to determine a maximum safe dose, which formed an "initial injection" of IL-12. Further studies in mice and cynomolgus monkeys revealed that an initial single dose of IL-12 prevented severe toxicity $[50,52]$. In addition, the route of administration may impact the toxicity of IL- 12 . In another two Phase I trials, the toxicities of IL-12 from subcutaneous injection appeared to be mild and consisted mainly of a flu-like syndrome [53, 54]. Subsequent clinical trials using lower doses of IL-12 with subcutaneous injection have shown no severe systemic toxicity $[20,55]$. Taken together, through the careful design of dosing regimen and administration method, the side effects of IL-12 can be minimized and acceptable.

\section{Conclusions}

In summary, these results demonstrate that IL-12, either alone or in combination with PTX + CDDP, mediated significant anti-tumor activity and showed 
more efficacy than did PTX + CDDP alone in these lung cancer models. This mechanism is dependent on the rapid production of IFN- $\gamma$ in activated NK cells, resulting in the inhibition of tumor angiogenesis. Hence, these findings may provide the basis for combination therapies to treat lung cancers, making this disease more accessible for targeted immune therapy. Although IL-12 has some side effects, through careful design of the dosing regimen and administration method, side effects can be minimized to acceptable levels, thus demonstrating that IL-12 is still a candidate for anticancer drugs.

\section{Additional files}

Additional file 1: Figure S1. Analysis of lung tumor nodes and tumor lung tissues weight in the four treatment groups. (A) The LLC tumor nodes and lung tissues were photographed. The visible tumor nodes were counted, and the final lung tumor tissues were photographed after completion of the treatments. The tumor and lung tissues as a whole were weighed. The average visible lung tumor nodes and the weight of LLC tumor and lung tissues from the IL-12 or PTX + CDDP + IL-12 group were significantly less than those of the PTX or control group $(n=3$; means $\pm \mathrm{SEM},{ }^{* *} P<0.01$ ). (B) The $\mathrm{CT} 26$ tumor nodes and lung tissues were photographed. The visible tumor nodes were counted, and the final lung tumor tissues were photographed after completion of the treatments. The tumor and lung tissues as a whole were weighed. The average visible lung tumor nodes and the weight of CT26 tumor and lung tissues from the IL-12 or PTX + CDDP + IL-12 group were significantly less than those of the PTX or control group ( $n=3$; means \pm SEM, ${ }^{* *} P<0.01$ ). (PDF $61 \mathrm{~kb}$ )

Additional file 2: Figure S2. PTX + CDDP induce LLC cell apoptosis in vitro but not in vivo at the same concentration. (A) LLC cells were examined by micro-imaging and Tunel assay. PTX + CDDP induced LLC cell apoptosis in vitro (original magnification, $\times 200$; scale bar, $50 \mu \mathrm{m}$ ). (B) Cryosections of tumor tissues were examined by Tunel. No apoptosis was detected in vivo in PTX + CDDP groups (original magnification, $\times 100$; scale bar, $100 \mu \mathrm{m})$. (PDF $129 \mathrm{~kb}$ )

Additional file 3: Figure S3. Spleens were enlarged after IL-12 treatment. (A) The spleen-size was calculated. The spleen-sizes increased significantly after IL-12 or PTX + CDDP + IL-12 treatment and were slightly reduced after PTX + CDDP treatment compared to the PTX + CDDP or the control groups ( $n=3$; means \pm SEM, $\left.{ }^{* *} P<0.01\right)$. (B) The spleens were weighed. The weights of spleens increased significantly after IL-12 or PTX + CDDP + IL-12 treatment compared to the PTX + CDDP or control groups $(n=3$; means \pm SEM, $\left.{ }^{*} P<0.05\right)$. (PDF $36 \mathrm{~kb}$ )

Additional file 4: Figure S4. Macrophage and T cell infiltration of tumors in the four treatment groups. Large number of $\mathrm{F} 4 / 80^{+}$ macrophages infiltrated the tumor tissues in the four groups (original magnification, $\times 100$; scale bar, $100 \mu \mathrm{m})$. Minimal infiltration of $\mathrm{CD}^{+} \mathrm{T}$ cells in tumor tissues in the four groups (original magnification, $\times 100$; scale bar, $100 \mu \mathrm{m}$ ). (PDF $159 \mathrm{~kb}$ )

Additional file 5: Figure S5. $\| \mathrm{L}-12$ treatment did not result in more invasive phenotype. (A) Matrix metalloprotein-9 (MMP-9) transcript level in para-carcinoma tissue was measured by quantitative PCR. MMP-9 transcript level was slightly decreased after $\mathrm{IL}-12$ treatment $(n=3$; means \pm SEM, $\left.{ }^{*} P<0.05\right)$. (B) Cadherin $1(\mathrm{CDH} 1)$ transcript level in para-carcinoma tissue was measured by quantitative PCR. Similar $\mathrm{CDH} 1$ transcript levels were found among the four groups. (PDF $5 \mathrm{~kb}$ )

\section{Funding}

This work was supported by grants from the Natural Science Foundation of China (\#81330071, \#31021061) and the National Basic Research Project (973 Project)(\#2012CB519004, 2013CB944902, and 2013CB530506). The funding agencies have no involvement with the design of the study and collection, analysis, interpretation of data and writing the manuscript.

\section{Availability of data and materials}

The datasets supporting the conclusions of this article are presented in the manuscript or additional files.

\section{Authors' contributions}

TY designed the experiments, TY carried out the experiments and wrote the manuscript, XDZ contributed to the molecular experiments, YLD contributed to the Flow cytometry analysis, $\mathrm{XHZ}$ contributed to the animal experiments, RS and ZGT contributed to the design of the study, HMW conceived of the study, and contributed to its design and coordination. All authors read and approved the final manuscript.

\section{Competing interests}

The authors declare that they have no competing interests.

\section{Ethics approval and consent to participate}

The animal experimental protocols were approved by the Ethics Committee of Animal Experiments of the University of Science and Technology of China (Approval Number: USTCACUC1201051). No human tissues or samples were used in this study.

\section{Author details}

${ }^{1}$ Institute of Immunology, School of Life Sciences, University of Science and Technology of China, Hefei, Anhui, China. ${ }^{2}$ Hefei National Laboratory for Physical Sciences at Microscale, University of Science and Technology of China, Hefei, Anhui, China.

Received: 28 July 2015 Accepted: 10 August 2016 Published online: 22 August 2016

\section{References}

1. Jemal A, Bray F, Center MM, Ferlay J, Ward E, Forman D. Global cancer statistics. CA Cancer J Clin. 2011;61(2):69-90. doi:10.3322/caac.20107.

2. Siegel R, Naishadham D, Jemal A. Cancer statistics, 2013. CA Cancer J Clin. 2013;63(1):11-30. doi:10.3322/caac.21166.

3. Dimitroulis J, Rapti A, Stathopoulos GP, Rigatos S, Stathopoulos J, Koutantos J, et al. Comparison of cisplatin-paclitaxel combination versus cisplatinetoposide in patients with small-cell lung cancer: a Phase III study. Oncol Rep. 2008;20(4):879-84.

4. Gupta N, Hatoum H, Dy GK. First line treatment of advanced non-small-cell lung cancer - specific focus on albumin bound paclitaxel. Int J Nanomedicine. 2014;9:209-21. doi:10.2147/IJN.S41770.

5. Rossi A, Chiodini P, Sun JM, O'Brien ME, von Plessen C, Barata F, et al. Six versus fewer planned cycles of first-line platinum-based chemotherapy for non-small-cell lung cancer: a systematic review and meta-analysis of individual patient data. Lancet Oncol. 2014; 15(11):1254-62. doi:10.1016/S1470-2045(14)70402-4

6. Liew MS, Sia J, Starmans MH, Tafreshi A, Harris S, Feigen M, et al. Comparison of toxicity and outcomes of concurrent radiotherapy with carboplatin/paclitaxel or cisplatin/etoposide in stage III non-small cell lung cancer. Cancer Med. 2013:2(6):916-24. doi:10.1002/cam4.142.

7. Spiro SG, Silvestri GA. One hundred years of lung cancer. Am J Respir Crit Care Med. 2005;172(5):523-9. doi:10.1164/rccm.200504-531OE.

8. Kobayashi M, Fitz L, Ryan M, Hewick RM, Clark SC, Chan S, et al. Identification and purification of natural killer cell stimulatory factor (NKSF), a cytokine with multiple biologic effects on human lymphocytes. J Exp Med. 1989;170(3):827-45

9. Stern AS, Podlaski FJ, Hulmes JD, Pan YC, Quinn PM, Wolitzky AG, et al. Purification to homogeneity and partial characterization of cytotoxic lymphocyte maturation factor from human B-lymphoblastoid cells. Proc Natl Acad Sci U S A. 1990;87(17):6808-12.

10. Trinchieri G. Interleukin-12 and the regulation of innate resistance and adaptive immunity. Nat Rev Immunol. 2003;3(2):133-46. doi:10.1038/nri1001. 
11. Del Vecchio M, Bajetta E, Canova S, Lotze MT, Wesa A, Parmiani G, et al. Interleukin-12: biological properties and clinical application. Clin Cancer Res. 2007;13(16):4677-85. doi:10.1158/1078-0432.CCR-07-0776.

12. Macatonia SE, Hsieh CS, Murphy KM, O'Garra A. Dendritic cells and macrophages are required for Th1 development of CD4+ T cells from alpha beta TCR transgenic mice: IL-12 substitution for macrophages to stimulate IFN-gamma production is IFN-gamma-dependent. Int Immunol. 1993;5(9): 1119-28.

13. Germann T, Gately MK, Schoenhaut DS, Lohoff M, Mattner F, Fischer S, et al. Interleukin-12/T cell stimulating factor, a cytokine with multiple effects on T helper type 1 (Th1) but not on Th2 cells. Eur J Immunol. 1993;23(8):1762-70. doi:10.1002/eji.1830230805

14. Langowski JL, Zhang X, Wu L, Mattson JD, Chen T, Smith K, et al. IL-23 promotes tumour incidence and growth. Nature. 2006;442(7101):461-5. doi:10.1038/nature04808

15. Eisenring M. vom Berg J, Kristiansen G, Saller E, Becher B. IL-12 initiates tumor rejection via lymphoid tissue-inducer cells bearing the natura cytotoxicity receptor NKp46. Nat Immunol. 2010;11(11):1030-8. doi:10.1038/ni.1947.

16. Le HN, Lee NC, Tsung K, Norton JA. Pre-existing tumor-sensitized T cells are essential for eradication of established tumors by $\mathrm{LL}-12$ and cyclophosphamide plus IL-12. J Immunol. 2001;167(12):6765-72.

17. Brunda MJ, Luistro L, Warrier RR, Wright RB, Hubbard BR, Murphy M, et al. Antitumor and antimetastatic activity of interleukin 12 against murine tumors. J Exp Med. 1993;178(4):1223-30.

18. Jaime-Ramirez AC, Mundy-Bosse BL, Kondadasula S, Jones NB, Roda JM, Mani $A$, et al. IL-12 enhances the antitumor actions of trastuzumab via NK cell IFN-gamma production. J Immunol. 2011;186(6):3401-9. doi:10.4049/ jimmunol.1000328.

19. Ansell SM, Witzig TE, Kurtin PJ, Sloan JA, Jelinek DF, Howell KG, et al. Phase 1 study of interleukin-12 in combination with rituximab in patients with B-cell non-Hodgkin lymphoma. Blood. 2002;99(1):67-74. doi:10.1182/blood. V99.1.67.

20. Little RF, Aleman K, Kumar P, Wyvill KM, Pluda JM, Read-Connole E, et al. Phase 2 study of pegylated liposomal doxorubicin in combination with interleukin-12 for AIDS-related Kaposi sarcoma. Blood. 2007;110(13):4165-71. doi:10.1182/blood-2007-06-097568.

21. Ardolino M, Azimi CS, lannello A, Trevino TN, Horan L, Zhang L, et al. Cytokine therapy reverses NK cell anergy in MHC-deficient tumors. J Clin Invest. 2014;124(11):4781-94. doi:10.1172/Jci74337.

22. Zitvogel L, Kroemer G. Cytokines reinstate NK cell-mediated cancer immunosurveillance. J Clin Invest. 2014;124(11):4687-9. doi:10.1172/ JCl78531.

23. Zhang D, Yang R, Wang S, Dong Z. Paclitaxel: new uses for an old drug. Drug Des Devel Ther. 2014;8:279-84. doi:10.2147/DDDT.S56801.

24. Dasari S, Tchounwou PB. Cisplatin in cancer therapy: molecular mechanisms of action. Eur J Pharmacol. 2014;740:364-78. doi:10.1016/j.ejphar.2014.07.025.

25. Wang Z. Selection of chemotherapy for non-small cell lung cancer is facilitated by new therapeutic strategies. Int J Clin Exp Med. 2014;7(11): 3833-42.

26. Hanna N, Shepherd FA, Fossella FV, Pereira JR, De Marinis F, von Pawel J, et al. Randomized phase III trial of pemetrexed versus docetaxel in patients with non-small-cell lung cancer previously treated with chemotherapy. J Clin Oncol. 2004;22(9):1589-97. doi:10.1200/JCO.2004.08.163.

27. Rupaimoole R, Wu SY, Pradeep S, Ivan C, Pecot CV, Gharpure KM, et al. Hypoxia-mediated downregulation of miRNA biogenesis promotes tumour progression. Nat Commun. 2014;5:5202. doi:10.1038/ ncomms6202.

28. Joshi HP, Subramanian IV, Schnettler EK, Ghosh G, Rupaimoole R, Evans C, et al. Dynamin 2 along with microRNA-199a reciprocally regulate hypoxia-inducible factors and ovarian cancer metastasis. Proc Natl Acad Sci U S A. 2014;111(14): 5331-6. doi:10.1073/pnas.1317242111.

29. Cao X, Leonard K, Collins LI, Cai SF, Mayer JC, Payton JE, et al. Interleukin 12 stimulates IFN-gamma-mediated inhibition of tumor-induced regulatory Tcell proliferation and enhances tumor clearance. Cancer Res. 2009;69(22): 8700-9. doi:10.1158/0008-5472.CAN-09-1145.

30. Kilinc MO, Aulakh KS, Nair RE, Jones SA, Alard P, Kosiewicz MM, et al. Reversing tumor immune suppression with intratumoral IL-12: activation of tumor-associated T effector/memory cells, induction of T suppressor apoptosis, and infiltration of CD8+ T effectors. J Immunol. 2006;177(10): 6962-73.
31. Tsung K, Meko JB, Tsung YL, Peplinski GR, Norton JA. Immune response against large tumors eradicated by treatment with cyclophosphamide and IL-12. J Immunol. 1998;160(3):1369-77.

32. Dowlati A, Crosby L, Remick SC, Makkar V, Levitan N. Paclitaxel added to the cisplatin/etoposide regimen in extensive-stage small cell lung cancer - the use of complete response rate as the primary endpoint in phase II trials. Lung Cancer. 2001;32(2):155-62.

33. Yu HK, Lee HJ, Yun SJ, Lee SJ, Langley RR, Yoon Y, et al. Antiangiogenic Therapy with Human Apolipoprotein(a) Kringle $V$ and Paclitaxel in a Human Ovarian Cancer Mouse Model. Transl Oncol. 2014;7(3):368-76. doi:10.1016/j. tranon.2014.04.005.

34. Lengyel E, Litchfield LM, Mitra AK, Nieman KM, Mukherjee A, Zhang Y, et al. Metformin inhibits ovarian cancer growth and increases sensitivity to paclitaxel in mouse models. Am J Obstet Gynecol. 2014. doi:10.1016/j.ajog. 2014.10.026

35. Kao CJ, Wurz GT, Monjazeb AM, Vang DP, Cadman TB, Griffey SM, et al. Antitumor effects of cisplatin combined with tecemotide immunotherapy in a human MUC1 transgenic lung cancer mouse model. Cancer Immunol Res. 2014:2(6):581-9. doi:10.1158/2326-6066.CIR-13-0205.

36. Bracci L, Schiavoni G, Sistigu A, Belardelli F. Immune-based mechanisms of cytotoxic chemotherapy: implications for the design of novel and rationale-based combined treatments against cancer. Cell Death Differ. 2014;21(1):15-25. doi:10.1038/cdd.2013.67.

37. Ramakrishnan R, Gabrilovich DI. Novel mechanism of synergistic effects of conventional chemotherapy and immune therapy of cancer. Cancer Immunol Immunother. 2013;62(3):405-10. doi:10.1007/s00262-012-1390-6.

38. Javeed A, Ashraf M, Riaz A, Ghafoor A, Afzal S, Mukhtar MM. Paclitaxel and immune system. Eur J Pharm Sci. 2009;38(4):283-90. doi:10.1016/j.ejps.2009. 08.009 .

39. Markasz L, Stuber G, Vanherberghen B, Flaberg E, Olah E, Carbone E, et al. Effect of frequently used chemotherapeutic drugs on the cytotoxic activity of human natural killer cells. Mol Cancer Ther. 2007:6(2):644-54. doi:10.1158/15357163.MCT-06-0358

40. Nastala $\mathrm{CL}$, Edington HD, McKinney TG, Tahara H, Nalesnik MA, Brunda $\mathrm{MJ}$, et al. Recombinant IL-12 administration induces tumor regression in association with IFN-gamma production. J Immunol. 1994:153(4): 1697-706.

41. Smyth MJ, Taniguchi M, Street SE. The anti-tumor activity of IL-12: mechanisms of innate immunity that are model and dose dependent. J Immunol. 2000;165(5):2665-70.

42. Segal JG, Lee NC, Tsung YL, Norton JA, Tsung K. The role of IFN-gamma in rejection of established tumors by IL-12: source of production and target. Cancer Res. 2002:62(16):4696-703.

43. Komita H, Homma S, Saotome H, Zeniya M, Ohno T, Toda G. Interferongamma produced by interleukin-12-activated tumor infiltrating CD8 + T cells directly induces apoptosis of mouse hepatocellular carcinoma. J Hepatol. 2006:45(5):662-72. doi:10.1016/j.jhep.2006.05.018.

44. Coughlin CM, Salhany KE, Gee MS, LaTemple DC, Kotenko S, Ma X, et al. Tumor cell responses to IFNgamma affect tumorigenicity and response to IL-12 therapy and antiangiogenesis. Immunity. 1998;9(1):25-34.

45. Paavonen K, Puolakkainen $\mathrm{P}$, Jussila L, Jahkola T, Alitalo K. Vascular endothelial growth factor receptor-3 in lymphangiogenesis in wound healing. Am J Pathol. 2000;156(5):1499-504. doi:10.1016/S00029440(10)65021-3.

46. Clarijs R, Schalkwijk L, Hofmann UB, Ruiter DJ, de Waal RM. Induction of vascular endothelial growth factor receptor-3 expression on tumor microvasculature as a new progression marker in human cutaneous melanoma. Cancer Res. 2002:62(23):7059-65.

47. Sgadari $C$, Angiolillo AL, Tosato $G$. Inhibition of angiogenesis by interleukin12 is mediated by the interferon-inducible protein 10. Blood. 1996;87(9): 3877-82.

48. Kanegane C, Sgadari C, Kanegane H, Teruya-Feldstein J, Yao L, Gupta G, et al. Contribution of the CXC chemokines IP-10 and Mig to the antitumor effects of IL-12. J Leukoc Biol. 1998:64(3):384-92.

49. Mitola S, Strasly M, Prato M, Ghia P, Bussolino F. IL-12 regulates an endothelial cell-lymphocyte network: effect on metalloproteinase-9 production. J Immunol. 2003;171(7):3725-33.

50. Leonard JP, Sherman ML, Fisher GL, Buchanan $\sqcup$, Larsen G, Atkins MB et al. Effects of single-dose interleukin-12 exposure on interleukin-12associated toxicity and interferon-gamma production. Blood. 1997;90(7): 2541-8. 
51. Cohen J. IL-12 deaths: explanation and a puzzle. Science. 1995;270(5238):908.

52. Sacco S, Heremans H, Echtenacher B, Buurman WA, Amraoui Z, Goldman M, et al. Protective effect of a single interleukin-12 (IL-12) predose against the toxicity of subsequent chronic IL-12 in mice: role of cytokines and glucocorticoids. Blood. 1997;90(11):4473-9.

53. Bajetta E, Del Vecchio M, Mortarini R, Nadeau R, Rakhit A, Rimassa L, et al. Pilot study of subcutaneous recombinant human interleukin 12 in metastatic melanoma. Clin Cancer Res. 1998;4(1):75-85.

54. Motzer RJ, Rakhit A, Schwartz LH, Olencki T, Malone TM, Sandstrom K, et al. Phase I trial of subcutaneous recombinant human interleukin-12 in patients with advanced renal cell carcinoma. Clin Cancer Res. 1998:4(5):1183-91.

55. Bekaii-Saab TS, Roda JM, Guenterberg KD, Ramaswamy B, Young DC, Ferketich AK, et al. A phase I trial of paclitaxel and trastuzumab in combination with interleukin-12 in patients with HER2/neu-expressing malignancies. Mol Cancer Ther. 2009:8(11):2983-91. doi:10.1158/1535-7163. Mct-09-0820.

Submit your next manuscript to BioMed Central and we will help you at every step:

- We accept pre-submission inquiries

- Our selector tool helps you to find the most relevant journal

- We provide round the clock customer support

- Convenient online submission

- Thorough peer review

- Inclusion in PubMed and all major indexing services

- Maximum visibility for your research

Submit your manuscript at www.biomedcentral.com/submit
Biomed Central 